\title{
Improvement of the Method of Control of Hydrate Formation Inhibitors in Laboratory Conditions
}

\section{Leontiev $\mathrm{S}^{*}$ and Drozdov A}

Tyumen Industrial University, Tyumen, Russia

*Corresponding author: Sergei Leontev, Tyumen industrial University, Republic street, 49/3, Tyumen, Russia, Tel: 8919930975; Email: leontevsa@tyuiu.ru

\section{Mini Review \\ Volume 4 Issue 5}

Received Date: July 27, 2020

Published Date: September 23, 2020

DOI: $10.23880 /$ ppej-16000235

\section{Abstract}

This article provides a description of the experiment with inhibitors of hydrate formation. The article describes the existing methodology, its scope and possible results. The article also provides experimental data that show that the boundaries of the method can be expanded due to different approaches to the formulation of the experiment in this method.

\section{Mini Review}

The method is based on the property of a mixture of water and tetrahydrofuran to form a hydrate at a temperature of about $4^{\circ} \mathrm{C}$, at normal atmospheric pressure. The essence of the method is a comparative analysis of hydrate formation inhibitors by placing them in a cell with a solution of tetrohydrofuran. At the moment, the method consists of mixing $80 \mathrm{~g}$ of the solution, with a fraction of THF in the solution of $15 \mathrm{~g}$ (about 18\%). At this concentration, the hydrate is formed with very strong mixing and a temperature of $2-3^{\circ} \mathrm{C}$.

The aim of the work was to find the minimum concentration of THF at which the hydrate is formed, as well as to determine the dependence on the intensity of mixing the solution.

To solve the problem, various concentrations of a THF solution without an inhibitor were mixed, and their rate of hydrate formation was determined. The results are shown in Figure 1.

Before placing them in a water bath, in which the temperature was maintained, the containers were strongly shaken, as this obviously greatly affects the process of hydrate formation. In four tanks the hydrate was formed simultaneously at different concentrations of THF in the solution $(1-18 \%, 7-12 \%, 2-23 \%, 3,3-27 \%$ from the mass of the solution). In the container 0 , no hydrate was formed, at a concentration of $6 \%$ THF. As a result, the hydrate was formed in four of the five containers at the same time, after 90 minutes, in one container was not formed during the entire experiment [1].

The second part of the experiment was to compare the effectiveness of the same amount of hydrate inhibitor at different concentrations of THF. The inhibitor dosage was $2 \%$ by weight of the solution. The results are shown in Table 1.

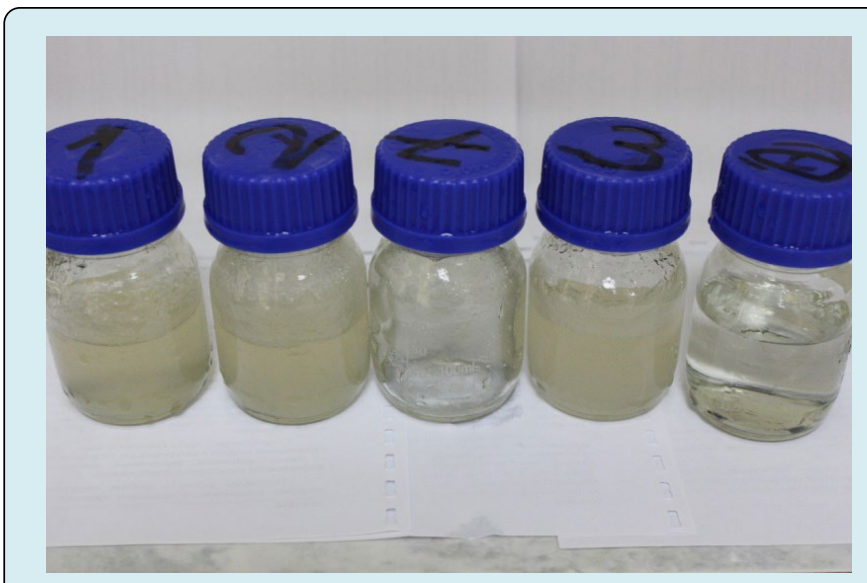

Figure 1: Results of the study of the dependence of hydrate formation on time. 


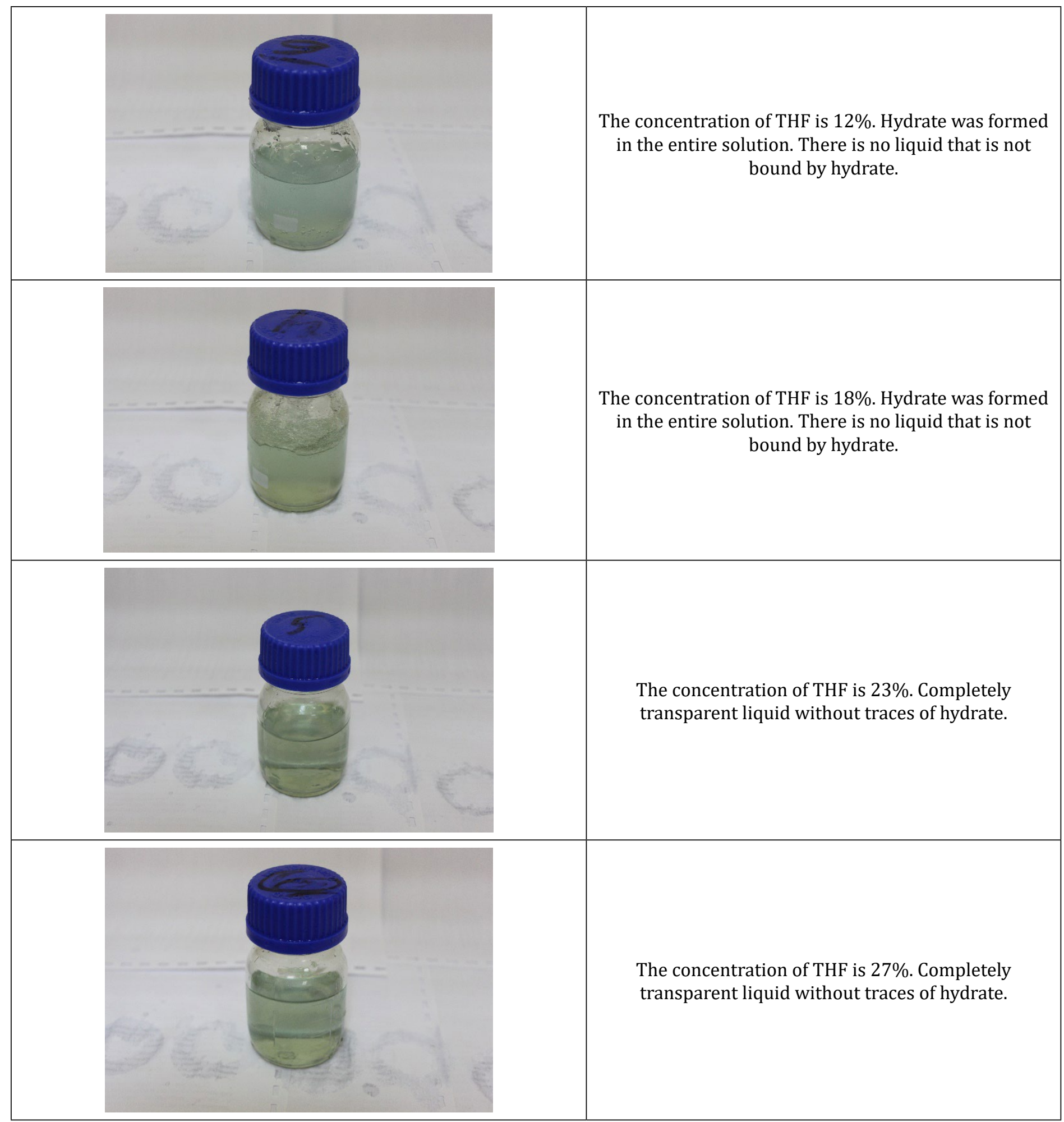

Table 1: The result of testing the hydrate formation inhibitor at different concentrations of THF [2].

\section{Conclusion}

Based on the experimental data obtained, the following conclusions can be drawn:
1. The amount of THF in the solution at which hydrate formation begins is $12 \%$, not $18 \%$, as stated in the method. 


\section{Petroleum \& Petrochemical Engineering Journal}

2. The hydrate formation time does not depend on the amount of THF in the solution.

3. The dependence of the inhibitor's effectiveness on the amount of THF in the solution is reversed. The same inhibitor, in the same concentration, manifests itself differently in different solutions. The higher the amount of THF, the better the inhibitor works. In fact, this opens up the possibility of research at high or low doses of inhibitors, at low concentrations of THF, which is not currently covered by the method.

\section{References}

1. Leontiev SA (2015) Technological calculation and selection of standard equipment for installations of systems for collecting and preparing well products. Tyumen State Oil and Gas University, Tyumen, Russia, pp: 123.

2. Galikeev RM (2010) Analysis of calculation methods for determining the oil saturation temperature with paraffin. New technologies for the fuel and energy sector of Western Siberia, pp: 312-316. 